\title{
Role of Gadd45a in Wip1-dependent regulation of intestinal tumorigenesis
}

\author{
ON Demidov ${ }^{1,2}$, Y Zhu' ${ }^{1}$, C Kek ${ }^{1}$, AR Goloudina ${ }^{2}$, N Motoyama ${ }^{3}$ and DV Bulavin ${ }^{\star, 1}$
}

Conversion of intestinal stem cells into tumor-initiating cells is an early step in $\mathrm{Apc}^{\mathrm{Min}}$-induced polyposis. Wild-type p53-induced phosphatase 1 (Wip1)-dependent activation of a DNA damage response and p53 has a permanent role in suppression of stem cell conversion, and deletion of Wip1 lowers the tumor burden in $\mathrm{Apc}^{\mathrm{Min}}$ mice. Here we show that cyclin-dependent kinase inhibitor 2a, checkpoint kinase 2, and growth arrest and DNA damage gene 45a (Gadd45a) exert critical functions in the tumor-resistant phenotype of Wip1-deficient mice. We further identified Gadd45a as a haploinsufficient gene in the regulation of Wip1-dependent tumor resistance in mice. Gadd45a appears to function through its ability to activate the Jnk-dependent signaling pathway that in turn is a necessary mediator of the proapoptotic functions of p53 that respond to activation of the $\beta$-catenin signaling pathway. We propose that silencing of Gadd45a is sufficient to override p53 activation in the presence of active $\beta$-catenin under conditions of an enhanced DNA damage response.

Cell Death and Differentiation (2012) 19, 1761-1768; doi:10.1038/cdd.2012.57; published online 4 May 2012

Conversion of normal cells into tumor-initiating cells is an initial step in the course of formation of any tumor. ${ }^{1}$ The majority of cells in an organism are terminally differentiated and thus are not capable of conversion into tumor-initiating cells, which requires cellular proliferation. In many instances, proliferative progenitors are programmed to divide only a few times before full differentiation; acquiring oncogenic mutations at this stage may also have a limited impact on tumorigenesis unless the mutation blocks differentiation. Increasing evidence in turn indicates that certain types of cancers originate from adult stem cells, the only proliferative cells that exist in the animal for a significant period of time that may be sufficient to accumulate oncogenic mutations. Several studies have demonstrated the role of adult stem cells as an origin of cancer, at least in certain tissues such as mouse intestine. $^{2}$ Stem cell-specific inactivation of Apc (adenomatous polyposis coli), the major regulator of tumorigenesis in the intestine, results in full-blown polyposis within a few weeks. ${ }^{3}$ In contrast, deletion of $A p c$ in proliferative progenitors or more differentiated cell types fails to induce sustainable cancer. $^{3}$

In many instances, activation of oncogenes in normal cells sets off the defense mechanisms to protect them from potential transformation. ${ }^{4}$ The major pathway that has had evolved to perform this function is controlled by a tumor suppressor p53. Depending on the strength of the signal, which in many cases relies on the type of oncogene, p53 activates apoptosis, transient or permanent cell cycle arrest called senescence. ${ }^{5}$ Modulation of $p 53$ levels and activity may therefore be critical to the regulation of cell susceptibility to oncogenic transformation. Regulation of p53 by various means to prevent oncogenic transformation may be especially important when particular oncogenic stimuli do not efficiently induce $\mathrm{p} 53$. For example, activation of the $\beta$-catenin signaling pathway readily induces p53 in vitro, but is not sufficient to activate apoptosis in the mouse intestine. ${ }^{6}$ Thus, in the absence of appreciable induction of p53, activation of the $\beta$-catenin signaling pathway leads to the conversion of intestinal stem cells (ISCs) into tumor-initiating cells and to the formation of polyps. On the other hand, lowering the threshold of p53 activation may induce efficient elimination of cells that have acquired oncogenic mutations, reducing the tumor burden in $\mathrm{ApC}^{\mathrm{Min}}$ mice. ${ }^{6}$

Activation of a DNA damage response is an important early step in suppression of tumorigenesis, including colorectal cancer. ${ }^{7} \mathrm{~A}$ similar response can be experimentally imposed by deletion of the wild-type p53-induced phosphatase 1 (Wip1) in mice, which results in activation of ataxia telangiectasia mutated (ATM) and its numerous downstream targets. Wip1 is a protein phosphatase $2 \mathrm{C}$ family serine/threonine phosphatase that has been implicated in regulation of several signaling pathways, including p53. The gene encoding Wip1, $P P M 1 D$, is located on chromosome 17q23 and is amplified in a variety of primary human tumors, negatively regulating

\footnotetext{
${ }^{1}$ Institute of Molecular and Cell Biology, Cell Cycle Control and Tumorigenesis Group, 61 Biopolis Drive, Proteos, Room 5-13, Singapore 138673, Singapore; ${ }^{2}$ INSERM UMR 866, Faculty of Medicine and Pharmacy, University of Burgundy, 7 Boulevard Jeanne d'Arc, Dijon 21033, France and ${ }^{3}$ Section of Molecular Aging, Department of Cognitive Brain Science Research Institute, National Center for Geriatrics and Gerontology 35, Gengo, Morioka, Obu Aichi 474-8511, Japan

${ }^{*}$ Corresponding author: DV Bulavin, Institute of Molecular and Cell Biology, Cell Cycle Control and Tumorigenesis Group, 61 Biopolis Drive, Proteos, Room 5-13, Singapore 138673, Singapore. Tel: +65 65869589; Fax: +65 67791117; E-mail: dvbulavin @imcb.a-star.edu.sg

Keywords: Wip1; gadd45a; intestinal stem cells; APC; cancer

Abbreviations: Wip1, wild-type p53-induced phosphatase 1; ATM, ataxia telangiectasia mutated; APC, adenomatous polyposis coli; gadd45a, growth arrest and DNA damage gene 45a; Cdkn2a, cyclin-dependent kinase inhibitor 2a; Chk2, checkpoint kinase 2; Lgr5, leucine-rich repeat-containing G-protein coupled receptor 5; IR, ionizing irradiation; GSK3, Glycogen synthase kinase 3; Mapk, mitogen-activated protein kinase; MKK7, mitogen-activated protein kinase kinase 7; IRES, internal ribosome entry site

Received 10.10.11; revised 30.3.12; accepted 02.4.12; Edited by M Oren; published online 04.5.12
} 
p53. ${ }^{10,11}$ Wip1 deletion leads to tumor suppression in several mouse models of cancer, including mammary gland tumors, B-cell lymphomas, intestinal polyposis, and spontaneous tumorigenesis. ${ }^{6,8,12}$ In the intestine, Wip1 expression was preferentially observed in ISCs at the position +4 from the bottom of the crypt. The Wip1-deficient ISCs appeared to be highly sensitive to various stresses, including stress generated in the presence of oncogenes. Wip1 deletion prevented ISC conversion into tumor-initiating cells in a model of $A p c^{M i n}$ induced intestinal cancer, suppressing tumorigenesis. In this model, Wip1 deletion lowered the threshold for p53 activation and eliminated ISCs by inducing apoptosis following activation of the $\beta$-catenin signaling pathway. The tumor-suppressive phenotype of Wip1-deficient mice was fully abrogated by simultaneous deletion of $p 53$. $^{6}$

In this work, we wished to identify the regulators of p53 that could suppress ISC conversion into tumor-initiating cells under conditions of an enhanced DNA damage response, such as occurs in the absence of Wip1. We determined that cyclin-dependent kinase inhibitor 2a (Cdkn2a), checkpoint kinase 2 (Chk2), and Gadd45a have an important role in the tumor-resistant phenotype of Wip1-deficient mice. We further show that Gadd45a (growth arrest and DNA damage gene $45 a)$ is a haploinsufficient gene that contributes to tumor resistance in Wip1-deficient mice. Gadd45a appears to function via its ability to activate the Jnk-dependent signaling pathway, which in turn mediates the proapoptotic functions of p53 following activation of the $\beta$-catenin signaling pathway. Thus, we propose that silencing of a single Gadd45a allele may be sufficient to override the DNA damage response in the presence of active $\beta$-catenin and may be an early event in the course of colorectal tumorigenesis.

\section{Results}

Both Lgr5-positive and Lgr5-negative ISCs are sensitive to activation of the $\beta$-catenin signaling pathway in Wip1deficient mice. Emerging lineage tracing data support the existence of two pools of adult stem cells in the mouse intestine. ${ }^{13,14}$ While new evidence suggests that the leucinerich repeat-containing G-protein coupled receptor 5 (Lgr5)positive cells at the base of the crypt provide lineage tracing in the intestine and may be ISCs, ${ }^{13}$ the long-standing paradigm is that the ISCs are distributed from positions +2 to $+6-7$ with majority of cells in position $+4 .{ }^{14}$ Lgr5-positive cells are also commonly found at position +4 , supporting the idea of overlap between various stem-cell markers. ${ }^{13}$

We previously found that Wip1 is preferentially located in +4 cells that express different markers of stem cells such as phospho-phosphatase and tensin homolog, Sox4 as well as retain ${ }^{3} \mathrm{H}$ thymidine. ${ }^{13}$ In turn, Wip1 deficiency results in enhanced apoptosis of the +4 ISCs in the presence of an active $\beta$-catenin signaling pathway, suppressing stem cell conversion into tumor-initiating cells and formation of polyps in an $A p c^{\mathrm{Min}}$ background. ${ }^{6}$ To ascertain the relevance of apoptotic cells in Wip1-deficient background to expression of another recently identified marker of stem cells, Lgr5, we crossed Wip1-deficient mice with mice carrying a cDNA for the enhanced green fluorescent protein (EGFP) knocked into the Lgr5 genomic locus (Lgr5-EGFP-IRES-creERT2 mice ${ }^{13}$ ). Subsequently, wild-type and Wip1-deficient mice, both expressing Lgr5-EGFP, were injected with a specific inhibitor of glycogen synthase kinase 3 (Gsk3) kinase, a kinase that induces phosphorylation-dependent degradation of $\beta$-catenin. ${ }^{6,15}$ These mice were analyzed for apoptosis $6 \mathrm{~h}$ later and we only scored GFP-positive crypts due to mosaic nature of Lgr5-EGFP-IRES-creERT2 mice. Consistent with previously published data, ${ }^{6}$ we found a significantly increased apoptosis in Wip1-deficient mice after injection of a Gsk3 inhibitor. On average, we found that $43 \%$ of apoptotic cells in Wip1-deficient mice were Lgr5-positive (Figure 1). Thus, both Lgr5-positive and Lgr5-negative ISCs undergo apoptosis in a Wip1-deficient background and therefore are accountable for suppression of polyp formation in the presence of active $\beta$-catenin pathway. ${ }^{6}$ Our data are also support the conclusion that Lgr5-positive population is more heterogeneous than originally proposed ${ }^{13}$ and contains a fraction of cells that are highly sensitive to activation of apoptosis.

Various signaling pathways control basal and oncogene-induced apoptosis of ISCs in Wip1-deficient mice. Deletion of Wip1 phosphatase results in enhanced p53dependent apoptosis of ISCs. ${ }^{6}$ We asked whether modulation of various signaling pathways could attenuate the basal
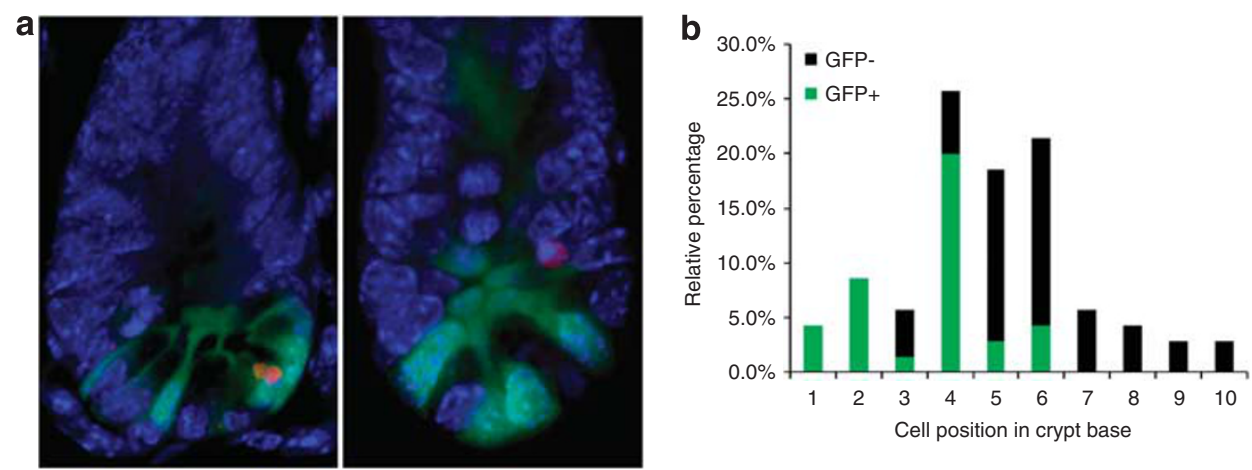

Figure 1 Wip1 is required for survival of Lgr5-positive and Lgr5-negative, + 4 ISCs. (a) Analysis of apoptosis (red) using TUNEL staining and confocal microscopy was carried out in Wip1-deficient mice crossed with Lgr5-EGFP-IRES-creERT2 mice and treated with Gsk3 inhibitor IX. Two representative pictures of double positive (left image) and apoptosis-positive, Lgr5-negative cells (right image) are shown. (b) Wip1-deficient mice carrying Lgr5-EGFP were treated with Gsk3 inhibitor IX and apoptosis of Lgr5positive (EGFP positive, green bars) and Lgr5-negative (EGFP negative, black bars) cells was plotted relative to the position in the crypt base 
a

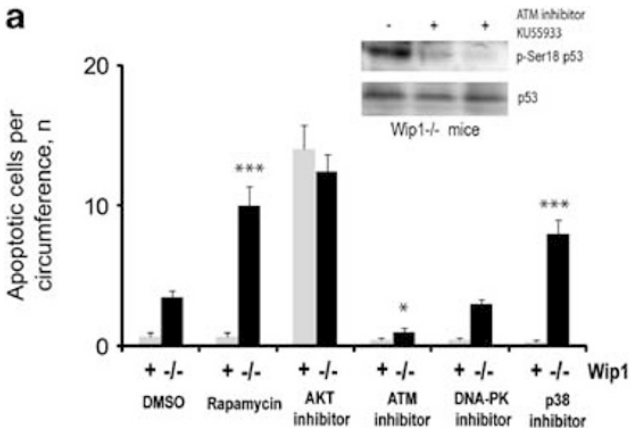

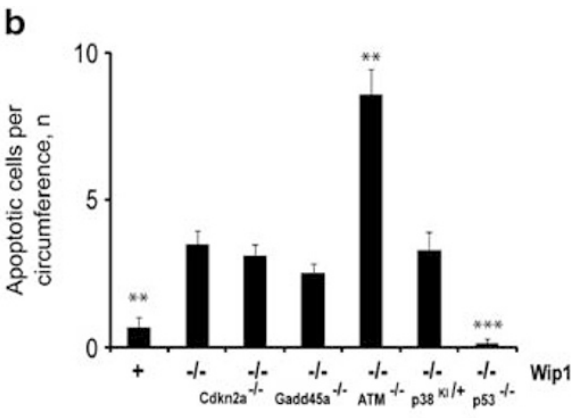

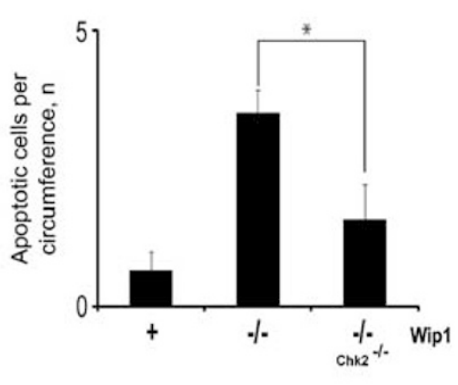

d $\left.{ }^{50}\right]$

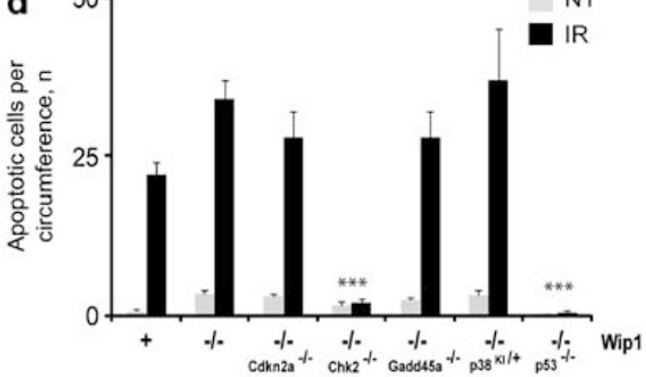

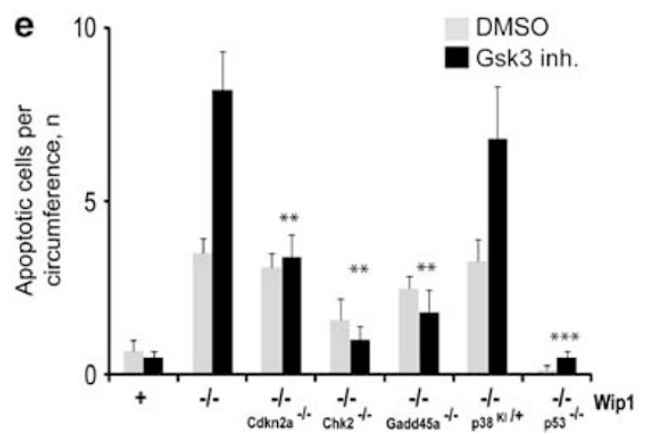

Figure 2 Multiple signaling pathways contribute to activation of apoptosis of ISCs in Wip1-deficient mice. (a) Analysis of apoptosis in the intestinal crypts based on scoring active caspase 3-positive cells was carried out in Wip1-deficient mice treated with different chemical inhibitors as shown in the panel. The inlet shows the analysis of phosphorylation of ATM target, p53 at Ser18 (human Ser15) in the presence of ATM inhibitor in intestinal crypts purified from Wip1-deficient mice. Two different samples are shown. (b and c) Mice of different genetic backgrounds were analyzed for spontaneous apoptosis in the intestinal crypts. Statistical significance is shown relative to the level of apoptosis in Wip1-deficient mice. (d) Apoptosis in the intestinal crypts of mice of different genetic backgrounds was analyzed $6 \mathrm{~h}$ after treatment of mice with $6 \mathrm{~Gy}$ of IR. Statistical significance is shown relative to the level of IR-induced apoptosis in Wip1-deficient mice. (e) Apoptosis in the intestinal crypts of mice of different genetic backgrounds was analyzed $12 \mathrm{~h}$ after treatment of mice with Gsk3 inhibitor IX. Statistical significance is shown relative to the level of Gsk3 inhibitor-induced apoptosis in Wip1-deficient mice. Significance levels: ${ }^{*} P<0.05 ;{ }^{* *} P<0.01 ;{ }^{* \star *} P<0.001$

apoptosis of ISCs in Wip1-deficient mice. Inactivation of DNA-PK after injecting Wip1-deficient mice with previously published effective concentrations of chemical inhibitors had no effect, while inactivation of mTOR, p38 mitogen-activated protein kinase (MAPK) and AKT further enhanced ISC apoptosis (Figure 2a). On the other hand, inactivation of ATM with chemical inhibitor KU55933 lowered the level of phosphorylation of ATM's downstream target, p53 Ser18 (human Ser15; Figure 2a) and was able to reduce the basal apoptosis in Wip1-deficient mice (Figure 2a). These results were consistent with the previously described role of Wip1 as a negative regulator of $\mathrm{ATM}^{8,16}$

To systematically address the role of different signaling pathways in regulation of enhanced apoptosis in Wip1deficient mice, we next analyzed genetically modified mice that had been backcrossed to a Wip1/Apc ${ }^{\text {Min }}$ background.
As we observed that chemical inhibition of ATM reduced basal apoptosis in Wip1-deficient intestines (Figure 2a), we crossed Wip1-deficient mice to an ATM-deficient background. Previous studies have shown that the $\beta$-catenin pathway activates p53 through $\mathrm{Cdkn} 2 \mathrm{a}^{17}$; we therefore generated mice that were deficient for both Wip1 and Cdkn2a. p38Mapk has also been described as a downstream target of Wip1 that may regulate apoptosis. To downregulate p38MAPK in Wip1deficient mice, we used a knock-in mouse strain expressing the dominant-negative $\mathrm{p} 38^{\mathrm{KI} /+}$ allele. ${ }^{18}$ We further decided to evaluate Gadd45a-deficient mice, as Gadd45a participates in regulation of the p38Mapk- and Jnk-dependent signaling pathways. ${ }^{19-21}$ In turn, Jnk is an important regulator of p53 and apoptosis under various conditions.

We found that inactivation of Cdkn2a, p38Mapk, and Gadd45a had no apparent effect on basal apoptosis in 
Wip1/Apc ${ }^{\mathrm{Min}}$ mice (Figure 2b). On the other hand, deletion of ATM further increased apoptosis, a result in contrast to the outcome of the experiments with an ATM inhibitor (Figure 2a). Although we cannot fully rule out off-target effects of ATM inhibitor, the potential differences may stem from the observation that deletion of ATM, in contrast to a chemical inhibitor, results in profound oxidative stress, which activates p53 and stress kinases including p38 Mapk. ${ }^{22}$ This activation may be further enhanced in a Wip1-deficient background, as Wip1 is a negative regulator of both $\mathrm{p} 53$ and P38MAPK, ${ }^{23}$ creating further toxicity in the intestine and thus enhancing apoptosis of ISCs. As such, we excluded ATM-deficient mice from further analysis due to the complexity of interpreting the results. However, to understand whether a signaling pathway downstream of ATM has a role in intestinal apoptosis in Wip1deficient mice, and considering the limitations of the use of ATM-deficient mice, we turned our attention to Chk2, a downstream target and important executor of ATM functions. ${ }^{24}$ Deletion of Chk2 does not exert an effect as deleterious as the enhanced oxidative damage described for ATM-deficient mice. ${ }^{25}$ Wip1-deficient mice were crossed into a Chk2-deficient background; the level of basal apoptosis in these double-mutant mice was reduced and was similar to the level in wild-type mice. This observation supports the idea that both ATM (Figure 2a) and Chk2 (Figure 2c) are involved in the regulation of basal apoptosis of ISCs in Wip1-deficient mice.

In many instances, Wip1 deficiency exerts its effects on cell cycle, apoptosis, and ultimately tumorigenesis through activation of ATM. ${ }^{8,16}$ ATM, in turn, is an integral part of a DNA damage response induced by ionizing irradiation (IR) and thus, the downstream molecules that attenuate basal apoptosis in Wip1-deficient intestines could also participate in IR signaling. To determine whether selected signaling pathways participate in regulation of IR-induced apoptosis in Wip1-deficient mice, we irradiated mice of various genetic backgrounds (as shown in Figure 1d) with $6 \mathrm{~Gy}$ of IR and evaluated apoptosis $6 \mathrm{~h}$ later. Consistent with the role of Wip1 in regulation of the DNA damage response, inactivation of only Chk2 and p53 reduced apoptosis in Wip1/Chk2 and Wip1/p53 double-deficient mice, respectively (Figure 2d). p38, Cdkn2a, and Gadd45a did not seem to execute the effects of IR on ISC apoptosis.

Tumors in $A p c^{M i n}$ mice arise from homozygous loss of the wild-type $A p c^{M i n}$ allele, resulting in constitutive activation of the $\beta$-catenin-Tcf/Lef signaling pathway. ${ }^{26}$ This activation may trigger an efficient $\mathrm{p} 53$ response, as does IR. ${ }^{17,26}$ To investigate how activation of $\beta$-catenin signaling modulates intestinal apoptosis, we treated wild-type and Wip1-deficient mice with Gsk3 inhibitor IX. We previously found that this inhibitor upregulates Tcf/Lef-dependent genes such as Ccnd1 (cyclin D1), Myc, and Cd44, and induces ISC apoptosis in Wip1-deficient mice. ${ }^{6}$ However, inhibitor treatment was not sufficient to activate ISC apoptosis in wild-type mice. ${ }^{6}$ Next, we turned to the analysis of Wip1-deficient mice crossed into various genetic backgrounds (Figure 2e). Wip1/Cdkn2a and Wip1/Gadd45a double-mutant mice did not activate apoptosis after treatment with the inhibitor of Gsk3. Deletion of Chk2 and p53 reduced basal as well as Gsk3 inhibitor IX-induced apoptosis in Wip1-deficient mice, while inactivation of $p 38$ had no effect. Taken together, our observations of the effects of chemical treatment and various genetic manipulations revealed that Wip1 deficiency activates basal apoptosis of ISCs in an ATM-Chk2-p53-dependent manner, while Gsk3 inhibitor IX-induced apoptosis is regulated through Cdkn2a and Gadd45a.

Cdkn2a, Chk2, and Gadd45a are involved in Wip1dependent regulation of $\boldsymbol{A p c}^{\mathrm{Min}}$-driven polyposis. We previously found that the ability of ISCs to undergo apoptosis in Wip1-deficient mice is an important initial step in suppression of ISC conversion into tumor-initiating cells and subsequent polyp formation. To elucidate the roles of various signaling pathways in the regulation of Wip1dependent suppression of polyposis, various genetically modified mice were backcrossed into a Wip1/Apc ${ }^{\text {Min }}$ background, and polyp formation was assessed in these mice at day 90. Deletion of Cdkn2a, Chk2, and Gadd45a reversed the tumor-resistant phenotype of Wip1/Apc ${ }^{\mathrm{Min}}$ mice (Figure 3a). The average numbers of polyps in Wip1/ Cdkn2a/Apc ${ }^{\text {Min }}$, Wip1/Chk2/Apc ${ }^{\text {Min }}$, and Wip1/Gadd45a/ $A p c^{\mathrm{Min}}$ mice were 49, 43, and 68, respectively. On the other hand, inactivation of p38Mapk did not affect polyposis, as Wip1/p38 ${ }^{K I /}+A p c^{\text {Min }}$ and Wip 1/Apc ${ }^{\text {Min }}$ mice had similar, low numbers of lesions (Figure $3 a$ ).

Deletion of Cdkn2a, Chk2, and p53 efficiently abrogates the tumor-resistant phenotype of Wip1-deficient mice in the model of $A p c^{M i n}$-induced polyposis; these observations are not unexpected, as disruption of these molecules attenuates
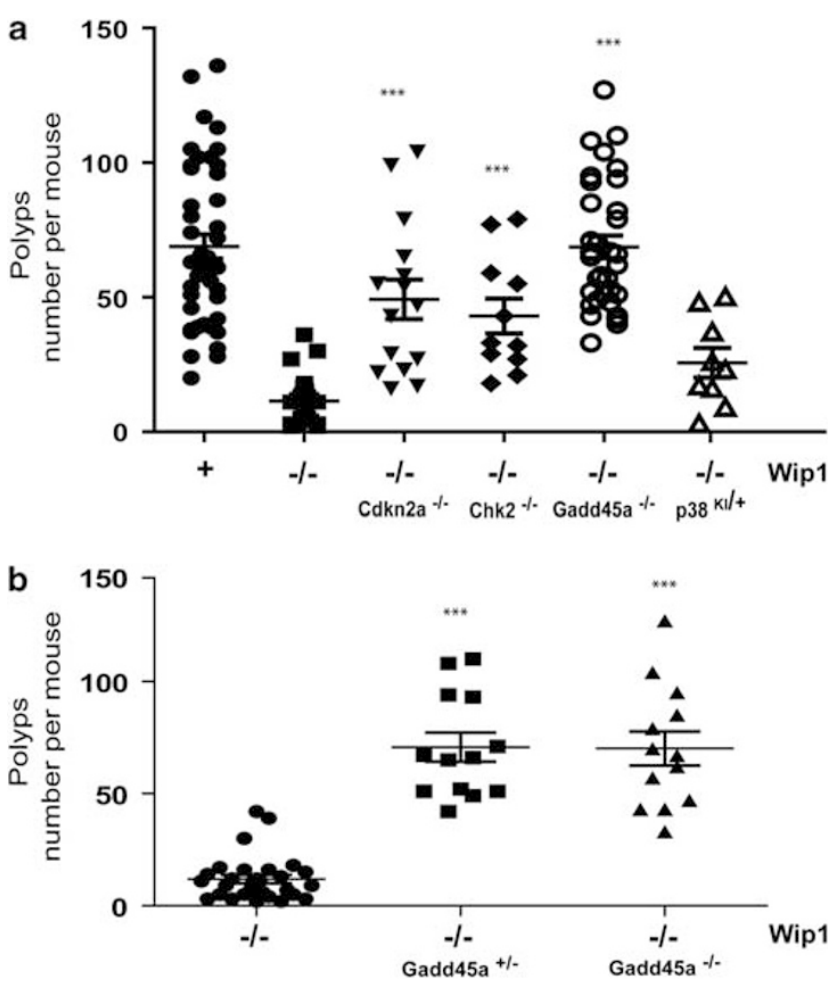

Figure 3 Multiple signaling pathways contribute to suppression of polyposis in Wip1-deficient mice. Mice of different genetic backgrounds, as shown in the panels $\mathbf{a}$ and $\mathbf{b}$, were analyzed for polyp formation at day 90 . Significance (relative to Wip1-deficient mice) levels: ${ }^{\star \star \star} P<0.001$ 
activation of p53. On the other hand, we were intrigued by our observation that Gadd45a deletion reverses the tumorresistant phenotype of Wip1-deficient mice, and we asked whether the presence of a single allele impacted tumorigenesis. Deletion of a single Gadd45a allele also reversed the tumor-resistant phenotype in Wip1-deficient mice (Figure 3b); the number of polyps that developed in Wip1/Apc ${ }^{\mathrm{Min}}$ mice heterozygous for Gadd45a was similar to the numbers in $A p c^{\text {Min }}$ and Gadd45a/Wip1/Apc ${ }^{\text {Min }}$-deficient mice, indicating that Gadd45a is haploinsufficient in the Wip1-dependent regulation of $A p c^{\mathrm{Min}}$-induced polyposis.

p53 activation decreases following $\beta$-catenin activation in mice with Cdkn2a, Chk2, or Gadd45a deletion. p53 regulates the conversion of stem cells into tumor-initiating cells, protecting against polyp formation in $A p c^{M i n}$ mice. ${ }^{6}$ Cdkn2a (through Arf) and Chk2 kinase are known positive regulators of p53 that mediate efficient p53 activation in the presence of various oncogenes. ${ }^{27,28}$ We checked whether disruption of Cdkn2a, Chk2, or Gadd45a resulted in attenuation of p53 activity in control mice and after treatment with Gsk3 inhibitor IX. We previously showed that induction of a p53 transcriptional target, p21, is fully dependent on the presence of $p 53$ in the mouse intestine and may serve as a read-out for p53 activity, which is otherwise difficult to evaluate in vivo. ${ }^{6}$ p21 mRNA levels in Cdkn2a/Wip1/Apc ${ }^{\text {Min }}$ and Chk2/Wip 1/Apc ${ }^{\mathrm{Min}}$-deficient mice were attenuated when compared to Wip1/Apc ${ }^{\text {Min }}$ mice (Figure 4). In a similar manner, we observed lack of activation of p21 mRNA in Gadd45/Wip 1/Apc ${ }^{\mathrm{Min}}$ mice, suggesting that the presence of Gadd45a is required for efficient p53 activation in response to stabilization of $\beta$-catenin. Thus, Chk2, Cdkn2a, and Gadd45a are required for efficient activation of p53 in the intestine of Wip1-deficient mice after treatment with an inhibitor of Gsk3.

Gadd45a is required for Jnk activation. Although Gadd45a has been previously implicated in the positive regulation of

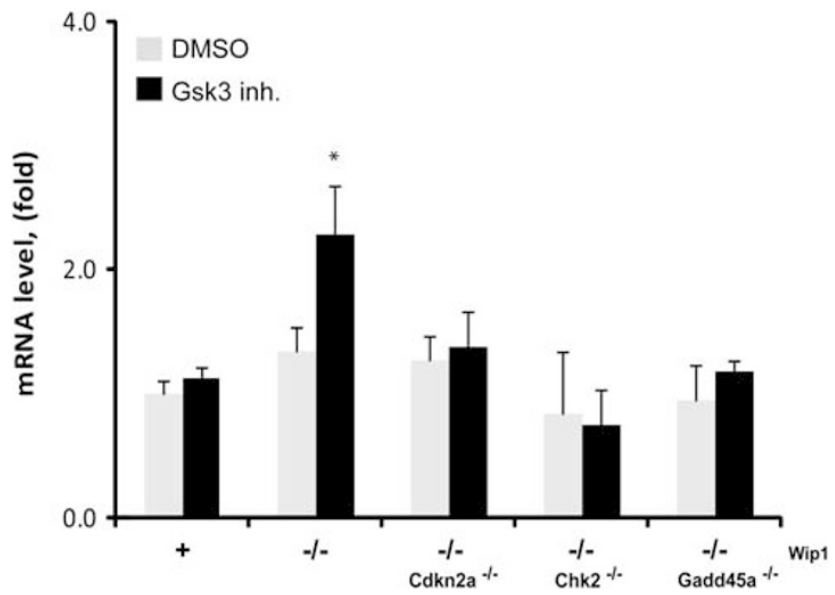

Figure 4 p53 activation in Wip1-deficient mice after the treatment with Gsk3 inhibitor IX is dependent on Cdkn2a, Chk2, and Gadd45a. Induction of p21 mRNA as a read-out of p53 activity in vivo was analyzed by real-time RT-PCR in the intestinal crypts $8 \mathrm{~h}$ after the treatment with Gsk3 inhibitor IX. Significance (relative to wild-type mice treated with Gsk3 inhibitor) level: ${ }^{\star} P<0.05$ p53, it is unknown how Gadd45a deficiency attenuates ISC apoptosis and reduces p53 activation in the presence of active $\beta$-catenin. Gadd45a has been previously implicated in the regulation of the stress-induced kinases Jnk and p38Mapk. ${ }^{19-21}$ As we determined that p38MAPK has no role in regulation of ISC apoptosis and intestinal tumorigenesis in Wip1-deficient mice (Figures 2 and 3), we concentrated on the Jnk-dependent pathway. Activation of the Jnk pathway has been implicated in p53 activation by various stresses; as reported previously, Jnk may mediate Gadd45a proapoptotic functions in some cell types, ${ }^{20,29}$ and thus be responsible for enhanced p53 activation after treatment with Gsk3 inhibitor IX in Wip1-deficient mice. To further evaluate this hypothesis, we analyzed the Jnk pathway in the intestinal epithelia of mice treated with Gsk3 inhibitor IX. Active Jnk activates c-Jun, a part of the AP1 transcriptional complex, and in turn c-Jun is under the control of AP1. We found that the expression of c-Jun mRNA increased when the mice were injected with the inhibitor, an upregulation that was fully dependent on the presence of Gadd45a, as its deletion efficiently reduced $c$-Jun mRNA upregulation in the intestine (Figure 5a).

To illustrate the relevance of our findings to human cancer, we analyzed the human RKO colorectal cell line. We used a subclone of RKO cells with a stably integrated Gadd45a antisense molecule to lower Gadd45a expression. Both cell lines were treated with Gsk3 inhibitor IX and evaluated for c-Jun phosphorylation as a read-out of Jnk-dependent signaling. We also assayed for activation of apoptosis. The basal level of c-Jun phosphorylation was significantly reduced in RKO Gadd45a antisense cells (Figure 5b). Further, induction of C-Jun phosphorylation $18 \mathrm{~h}$ after treatment with Gsk3 inhibitor IX was also significantly lower in RKO Gadd45a antisense cells versus the control cell line. Gsk3 inhibitor IX treatment induced efficient apoptosis of RKO cells, which was significantly attenuated when Gadd45a expression was silenced by the antisense (Figure $5 \mathrm{c}$ ). In a similar manner, we found that treatment of RKO cells with R-spondin and Wnt3a ligand results in efficient accumulation of $\beta$-catenin and this was sufficient to activate a robust apoptosis in RKO cells, but not in cells expressing Gadd45a antisense (Figure 5d). The attenuation of cell death by Gadd45a antisense was also accompanied by loss of induction of p53 target proapoptotic genes Pmaip1 and Bax after Gsk3 inhibition (Figure 5e).

To understand whether lack of Jnk signaling is responsible for reduced activation of p53 in Gadd45a AS RKO cells, next we transfected cells with a vector carrying an upstream activator of Jnk, mitogen-activated protein kinase kinase 7 (MKK7), and analyzed activation of p53 under different conditions. We found that both p53 phosphorylation at activating site, Ser6, ${ }^{30}$ and $p 53$ reporter activity were robustly induced in the presence of Gsk3 inhibitor only in RKO but not in RKO Gadd45a AS cells (Figure 5f). In turn, introduction of MKK7 was able to enhance both p53 Ser6 phosphorylation and reporter activity in RKO Gadd45a AS cells to the level comparable with RKO cells (Figure 5f). Our data are consistent with the recent report regarding the role of MKK7 in regulation of p53 activation and tumorigenesis. ${ }^{30}$ Thus, attenuation of Gadd45a levels leads to decreased activation of the Jnk-p53 pathway and lowers the level of apoptosis in 

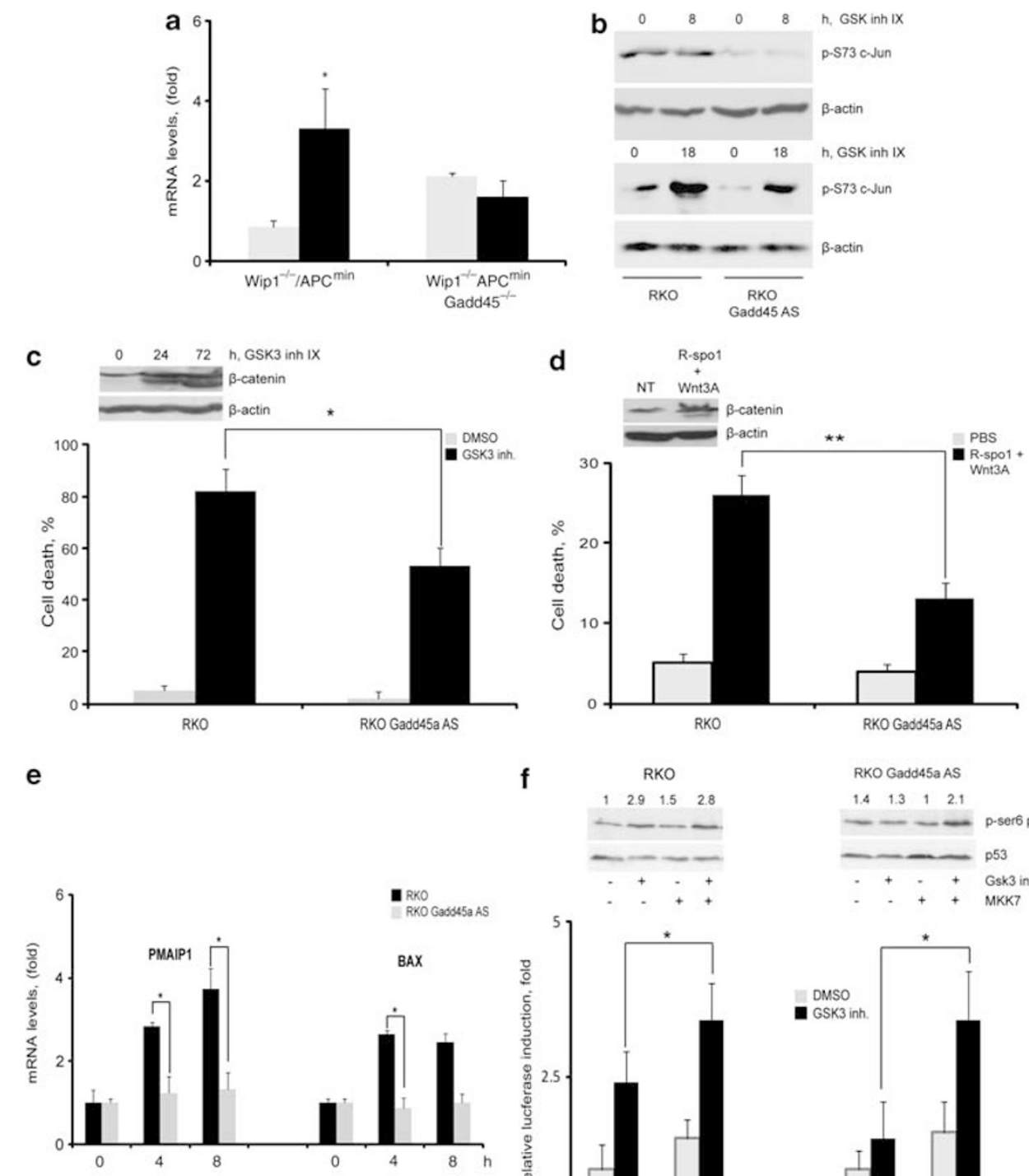

f

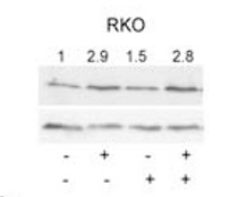

RKO Gadd45a AS

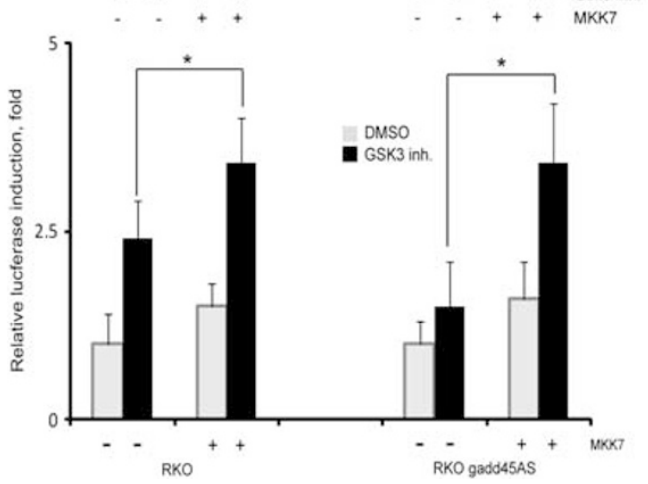

Figure 5 Gadd45a regulates Jnk signaling pathway. (a) The level of expression of c-Jun mRNA as a read-out of jnk activity in vivo was analyzed by real-time RT-PCR in intestinal crypts of different genotypes after the treatment with Gsk3 inhibitor IX (black columns). Statistical significance was analyzed relative to the level of c-jun in non-treated Wip1-deficeint mice (white columns). (b) Phosphorylation of Jnk target c-Jun at serine 73 was analyzed in RKO and RKO Gadd45a AS cells after the treatment with Gsk3 inhibitor IX after $8 \mathrm{~h}$ (upper panel) and $18 \mathrm{~h}$ (lower panel). (c) Accumulation of $\beta$-catenin was analyzed by western blotting after the treatment of RKO cells with GSK inhibitor IX (top panel). Cell death was analyzed by GuavaViaCount as described in Materials and Methods in RKO and RKO Gadd45a AS cells $18 \mathrm{~h}$ after the treatment with Gsk3 inhibitor IX (lower panel). Significance level: ${ }^{*} P<0.05$. (d) Accumulation of $\beta$-catenin was analyzed by western blotting after the treatment of RKO cells with R-spondin and Wnt3a ligand (top panel). Cell death was analyzed by GuavaViaCount in RKO and RKO Gadd45a AS cells $18 \mathrm{~h}$ after the treatment with R-spondin and Wnt3a ligand (bottom graph). Significance level: ${ }^{* \star} P<0.01$. (e) Attenuated induction of p53 targets genes PMAIP1 and BAX at 4 and $8 \mathrm{~h}$ after the treatment with Gsk3 inhibitor IX in RKO cells with Gadd45a antisense. mRNA levels were analyzed by real-time RT-PCR. Significance level: ${ }^{*} P<0.05$. (f) Analysis of $p 53$ phosphorylation at Ser6 was carried out in RKO and RKO Gadd45a AS cells that were either treated with Gsk3 inhibitor XI, transfected with MKK7 vector or both. In parallel, the level of p53 transactivation activity was analyzed under different conditions using Luciferase reporter containing p53 response elements in the promoter as described in the panel and Materials and Methods. Significance level: ${ }^{*} P<0.05$

response to treatment with Gsk3 inhibitor IX, both in mouse (Figures 2-4) and in human (Figure 5) cells.

\section{Discussion}

Recent studies have revealed the existence of tumorigenesis barriers that slow or inhibit the progression of preneoplastic lesions to neoplasia. ${ }^{27,31}$ Activation of a DNA damage response represents one of such barriers that is operational in various cancers, including colorectal tumors. ${ }^{27}$ Inhibition of the DNA double-strand break response kinase ATM in a mouse model led to increased tumor size and invasiveness. ${ }^{32}$ Modulating the conditions of enhanced DNA damage responses may therefore provide an interesting approach for understanding tumor evolution as well as the sequence of events that must occur for tumor progression. 
p53 is a major tumor suppressor that is frequently mutated in human colorectal cancers; however, this genetic change occurs only in later stages of tumorigenesis. ${ }^{33}$ Consistent with p53 function only in advanced colorectal cancer, p53 deletion does not affect the number of polyps in the $\mathrm{Apc}^{\mathrm{Min}}$ mouse model of intestinal tumorigenesis, ${ }^{6}$ which mimics pathogenesis of familial adenomatous polyposis in humans. In contrast, emerging data strongly support the hypothesis that p53 upregulation may efficiently suppress intestinal tumorigenesis. Deletion of Mdm2 or Wip1 phosphatase, two negative regulators of $\mathrm{p53}$, results in $\mathrm{p} 53$ upregulation and suppression of $\mathrm{Apc}^{\mathrm{Min}}$-induced polyposis in mice. 6,34 This effect, at least in Wip1-deficient mice, appeared to be at the level of regulation of ISC conversion into cancer stem cells. ${ }^{6}$

It has become increasingly clear that a primary function of Wip1 is the repression of several signaling pathways within the DNA damage-response network in which various molecules have been shown to be direct targets of Wip1. In addition to inhibiting p38MAPK after UV radiation, ${ }^{23}$ Wip1 has been shown to dephosphorylate numerous molecules within the ATM-dependent signaling network including ATM itself ${ }^{8,16}$ and Chk2, ${ }^{9}$ downstream of ATM. On the basis of these observations, we used Wip1-deficient mice as a model system to understand the contribution of an enhanced DNA damage response to the initial steps of tumorigenesis.

If DNA damage occurs during the early stages of colorectal cancer, the tumor cell must find ways to overcome this barrier in order to develop into a full-blown cancer. In many instances, this initial step involves the loss or mutation of p53, which appears not to be the case for human colorectal cancer. ${ }^{33}$ Here we identified loss of Gadd45a to be essential for cell to survive p53 activation in response to active $\beta$-catenin signaling pathway. We demonstrated that Gadd45a feeds into the Jnk-dependent signaling pathway to activate p53 when $\beta$ catenin is active. Consistent with this observation, Gadd45a deletion accelerates Ras- and Myc-driven mammary tumor formation, potentially through regulation of Jnk-induced apoptosis, ${ }^{29,35}$ while MKK7-Jnk signaling pathway is required for activation of p53 in several mouse models of cancer. ${ }^{30}$

It is important to note that Gadd45a deletion specifically affected $\beta$-catenin-induced activation but did not completely inactivate the Jnk-dependent signaling pathway. As a result, activation of ISC apoptosis induced by Gsk3 inhibitor IX was specifically diminished in Gadd45a-deficient cells. In contrast, full inactivation of Jnk may exert the opposite effect and suppress $\mathrm{Apc}^{\mathrm{Min}}$-induced tumorigenesis through inactivation of TCF4-dependent transcription. ${ }^{36}$ In the case of Gadd45adeficient mice, Gsk3 inhibitor-induced Jnk activation was reduced; however, activation of TCF4 downstream targets such as c-Myc, cyclin D1, and CD44 was comparable with other genotypes (data not shown). Thus, lack of Gadd45a may provide a selective advantage for ISC survival and tumor development through suppression of Jnk-dependent activation of $\mathrm{p} 53$ when $\beta$-catenin is stabilized.

In conclusion, our extensive genetic analysis of $A p c^{M i n}$ mice under conditions of an enhanced DNA damage response in Wip1-deficient mice underlines the importance of Gadd45a in the suppression of intestinal tumorigenesis. Loss of Gadd45a may therefore be an early event in the course of human colorectal cancer.

\section{Materials and Methods}

Mouse strains. All animal protocols used in this study were approved by the Institute of Molecular and Cell Biology Animal Safety and Use Committee. Wip1-/-, p53-I-, ATM-I-, Chk2-I-, Cdkn2a-/-, and p38 knock-in mice were previously described. ${ }^{6,8,25,29} \mathrm{Apc}^{\text {Min }}$ heterozygous and Lgr5EGFP-IRES-creERT2 mice $^{13}$ were obtained from the Jackson Laboratory (Bar Harbor, ME, USA). We crossed Wip1 + I - mice with Apc ${ }^{\text {Min }}$ with mice of different genotypes to obtain mice for the analysis in this study. Mice were euthanized and polyps were counted at day 90 .

Immunohistochemistry. Formalin-fixed paraffin-embedded mouse intestinal samples were sectioned at $5 \mu \mathrm{m}$ and mounted on coated slides. Following dewaxing and re-hydration, sections were pretreated with peroxidase blocking buffer $\left(3 \% \mathrm{H}_{2} \mathrm{O}_{2}\right.$ in methanol) for $20 \mathrm{~min}$ at room temperature. Antigen retrieval was performed by autoclaving samples in Sodium Citrate buffer ( $10 \mathrm{mM}, \mathrm{pH} 6.0)$ for $30 \mathrm{~min}$. Blocking of nonspecific binding was performed using $3 \%$ BSA or $5 \%$ blocking reagent (Roche, Indianapolis, IN, USA) for $30 \mathrm{~min}$ at RT. The rabbit anti-caspase-3 (1:300; AF835, R\&D Systems, Minneapolis, MN, USA) were used in all experiments. The Envision + kit (Dako, Glostrup, Denmark) was used as a secondary reagent.

To analyze apoptosis in Lgr5-EGFP-IRES-creERT2 mice, small intestine was cut into 12 segments with equal length, aligned parallel and cryo-sectioned to $18-\mu \mathrm{m}$ coronal sections. TUNEL assay was performed according to the manufacturer protocol (Millipore, Billerica, MA, USA, S7165). Briefly, sections were washed in PBS three times then immerged in equilibration buffer for $1 \mathrm{~min}$. After removal of the equilibration buffer, terminal deoxynucleotidyl transferase enzyme in reaction butter was applied to label damaged DNA with dUTP-digoxigenin. Reaction was carried out in $37^{\circ} \mathrm{C}$ for $2 \mathrm{~h}$, and an anti-digoxigenin antibody conjugated with a rhodamine fluorochrome was used to visualize apoptotic cells. Cell number and positions and co-localization with EGFP was analyzed using the inverted confocal Zeiss (Berlin, Germany) LSM700 and LSM image browser.

Real time RT-PCR. mRNA expression was determined by Real-Time PCR. Tissues were frozen in dry ice and RNA was extracted using the TRlzol reagent (Invitrogen, Carlsbad, CA, USA). Reverse transcription was performed using Superscript II (Invitrogen) according to the manufacturer instructions. Real-Time PCR was performed at LightCycler 2.0 Real-Time PCR System (Roche) with LightCycler FastStart DNA MasterPlus SYBR Green I (Roche). GAPDH and HRPT mRNA levels were used as a reference. We used the following primers: p21 5'-TTGCACTCTGGTGTCTGAGC-3'; 5'-AGGGCCCTACCGTCCTACTA-3'. c-jun, 5'-AGCAGGGACCCATGGAAGTT-3', and 5'-AAAGATGACCTTTGCTTGTGCA T-3'. To analyze PMAIP1, BAX, Actin mRNA expression in RKO cells, we used Solaris Gene Expression Assay (Dharmacon , Lafayette, CO, USA) and 7500 Fast Real-time PCR system (Applied Biosystem, Foster City, CA, USA).

Inhibitors. Mice were injected i.p. with the Rapamycin ${ }^{37}$ (Sigma-Aldrich, St. Louis, MO, USA, \#R0395) $7.5 \mathrm{mg}$ per $\mathrm{kg}$ of body weight in $5 \%$ DMSO or AKT inhibitor ${ }^{38}$ (NSC 154020, Calbiochem, Millipore) $20 \mathrm{mg}$ per $\mathrm{kg}$ of body weight in $5 \%$ DMSO or ATM inhibitor (KU55933, Calbiochem, Millipore) $15 \mathrm{mg}$ per $\mathrm{kg}$ of body weight in $5 \%$ DMSO or DNA-PK inhibitor ${ }^{39}$ (NU7026, Sigma-Aldrich) $15 \mathrm{mg}$ per $\mathrm{kg}$ of body weight in 5\% DMSO or p38MAPK inhibitor ${ }^{12}$ (SB202190, SigmaAldrich) $10 \mathrm{mg}$ per $\mathrm{kg}$ of body weight in $5 \%$ DMSO, or GSK-3 inhibitors IX ${ }^{6}$ (Calbiochem, Millipore) $15 \mathrm{mg}$ per $\mathrm{kg}$ of body weight in $5 \%$ DMSO. After 6,10 , or $12 \mathrm{~h}$, mice were euthanized and organs were collected for subsequent analysis. To induce activation of $\beta$-catenin RKO and RKO Gadd45 AS cells were treated with 10- $\mu \mathrm{M}$ GSK-3 inhibitors IX (Calbiochem, Millipore) or with combination of $500 \mathrm{ng} / \mathrm{ml} \mathrm{R}$-spondin1 and $200 \mathrm{ng} / \mathrm{ml}$ Wnt3A (both from R\&D Systems).

Cell death assay. The number of dead cells was estimated by the cell death assay using the Guava ViaCount Reagent (Millipore). Cells were trypsinized, washed with PBS solution, and stained with Guava ViaCount Reagent for $5 \mathrm{~min}$. The percentage of dead cells was measured by using Guava EasyCyte Plus Flow Cytometry System (Millipore) and analyzed by using Guava ViaCount Software.

Luciferase assay. Transient transfections of RKO and RKO Gadd45 AS cells were performed using JetPEI (Polyplus, Illkirch, France), $2000 \mathrm{ng}$ of pBabe or pBabe-MKK7, $400 \mathrm{ng}$ of the p53-3xRE-luc Firefly luciferase reporter construct and $20 \mathrm{ng}$ pRL-TK Renilla luciferase as reference vector (Promega, Madison, WI, USA) per $5 \times 10^{5}$ cells. Thirty hours after transfection, cells were treated with GSK3 
inhibitor IX (Calbiochem, Millipore). After additional $16 \mathrm{~h}$ of incubation, cells were collected and measured for Firefly and Renilla luciferase activities using the Dual Luciferase Assay System (Promega) on LUMAT LB9507 luminometer. Results represent the average standard deviations of two independent experiments.

Western blot analysis. The RKO and RKO gadd45 AS cell lines were purchased from ATCC (Manassas, VA, USA). Cell lysates containing $50 \mu \mathrm{g}$ of protein were analyzed by western blot using anti-phospho-c-Jun (Ser73) antibody, anti-phospho-p53 (Ser6) antibody (Cell Signaling, Danvers, MA, USA), anti-p53 D01 (Santa Cruz Biotechnology, Santa Cruz, CA, USA), anti- $\mu$-catenin (BD Transduction Laboratories, San Jose, CA, USA) and anti-actin antibody (SigmaAldrich, A 2103). To analyze phosphorylation status of p53 in human cells, RKO cells were treated with $25 \mu \mathrm{M}$ of proteosomal inhibitor MG-132 (Sigma-Aldrich) for $3 \mathrm{~h}$ before harvesting.

Small intestinal crypts were isolated from adult mice of $6-12$ weeks as described before. ${ }^{8}$ Crypt lysates containing $100 \mu \mathrm{g}$ of protein were analyzed by western blot using anti-phospho-p53 (Ser18) (AnaSpec, Fremont, CA, USA) and anti-p53 CM5 (Novocastra, Newcastle upon Tyne, UK). Secondary antibodies were from Jackson Immuno Research (West Grove, PA, USA). Immunoreactivity was detected using Western Blotting Luminol Reagent (Santa Cruz Biotechnology). We used GeIQuant.NET software provided by biochemlabsolutions.com to calculate relative intensity of bands. p-Ser6 p53 band average-corrected intensity by total p53 band was presented.

\section{Conflict of Interest}

The authors declare no conflict of interest.

Acknowledgements. The research for DVB was supported by the Agency for Science, Technology and Research (Singapore) and for OND partially by Conseil Regional de Bourgogne. We are grateful to Dr. Penninger for providing an MKK7 vector.

1. Pardal R, Clarke MF, Morrison SJ. Applying the principles of stem-cell biology to cancer. Nat Rev Cancer 2003; 3: 895-902.

2. Reya T, Morrison SJ, Clarke MF, Weissman IL. Stem cells, cancer, and cancer stem cells. Nature 2001; 414: 105-111.

3. Barker N, Ridgway RA, van Es $\mathrm{JH}$, van de Wetering $\mathrm{M}$, Begthel $\mathrm{H}$, van den Born $\mathrm{M}$ et al. Crypt stem cells as the cells-of-origin of intestinal cancer. Nature 2009; 457 : 608-611.

4. Pietsch EC, Sykes SM, McMahon SB, Murphy ME. The p53 family and programmed cell death. Oncogene 2008; 27: 6507-6521.

5. Horn HF, Vousden KH. Coping with stress: multiple ways to activate p53. Oncogene 2007; 26: $1306-1316$.

6. Demidov ON, Timofeev O, Lwin HN, Kek C, Appella E, Bulavin DV. Wip1 phosphatase regulates $\mathrm{p53}$-dependent apoptosis of stem cells and tumorigenesis in the mouse intestine. Cell Stem Cell 2007; 1: 180-190.

7. Bartkova J, Rezaei N, Liontos M, Karakaidos P, Kletsas D, Issaeva N et al. Oncogeneinduced senescence is part of the tumorigenesis barrier imposed by DNA damage checkpoints. Nature 2006; 444: 633-637.

8. Shreeram S, Hee WK, Demidov ON, Kek C, Yamaguchi H, Fornace AJ Jr. et al. Regulation of ATM/p53-dependent suppression of myc-induced lymphomas by Wip1 phosphatase. J Exp Med 2006; 203: 2793-2799.

9. Fujimoto H, Onishi N, Kato N, Takekawa M, Xu XZ, Kosugi A et al. Regulation of the antioncogenic Chk2 kinase by the oncogenic Wip1 phosphatase. Cell Death Differ 2006; 13: $1170-1180$.

10. Bulavin DV, Demidov ON, Saito S, Kauraniemi P, Phillips C, Amundson SA et al. Amplification of PPM1D in human tumors abrogates p53 tumor-suppressor activity. Nat Genet 2002; 31: 210-215.

11. Li J, Yang Y, Peng Y, Austin RJ, van Eyndhoven WG, Nguyen KC et al. Oncogenic properties of PPM1D located within a breast cancer amplification epicenter at 17q23. Nat Genet 2002; 31: 133-134.

12. Bulavin DV, Phillips C, Nannenga B, Timofeev O, Donehower LA, Anderson CW et al. Inactivation of the Wip1 phosphatase inhibits mammary tumorigenesis through p38 MAPK-mediated activation of the p16(Ink4a)-p19(Arf) pathway. Nat Genet 2004; 36: 343-350.
13. Barker $\mathrm{N}$, van Es $\mathrm{JH}$, Kuipers $\mathrm{J}$, Kujala $\mathrm{P}$, van den Born $\mathrm{M}$, Cozijnsen $\mathrm{M}$ et al. Identification of stem cells in small intestine and colon by marker gene Lgr5. Nature 2007; 449: 1003-1007.

14. Sangiorgi $E$, Capecchi MR. Bmi1 is expressed in vivo in intestinal stem cells. Nat Genet 2008; 40: 915-920.

15. Salic A, Lee E, Mayer L, Kirschner MW. Control of beta-catenin stability: reconstitution of the cytoplasmic steps of the wnt pathway in Xenopus egg extracts. Mol Cell 2000; 5: 523-532.

16. Shreeram S, Demidov ON, Hee WK, Yamaguchi H, Onishi N, Kek C et al. Wip1 phosphatase modulates ATM-dependent signaling pathways. Mol Cell 2006; 23: 757-764.

17. Damalas A, Ben-Ze'ev A, Simcha I, Shtutman M, Leal JF, Zhurinsky J et al. Excess beta-catenin promotes accumulation of transcriptionally active p53. EMBO J 1999; 18: 3054-3063.

18. Wong ES, Le Guezennec X, Demidov ON, Marshall NT, Wang ST, Krishnamurthy J et al. p38MAPK controls expression of multiple cell cycle inhibitors and islet proliferation with advancing age. Dev Cell 2009; 17: 142-149.

19. Bulavin DV, Kovalsky O, Hollander MC, Fornace AJ Jr. Loss of oncogenic H-ras-induced cell cycle arrest and p38 mitogen-activated protein kinase activation by disruption of Gadd45a. Mol Cell Biol 2003; 23: 3859-3871.

20. Hildesheim J, Bulavin DV, Anver MR, Alvord WG, Hollander MC, Vardanian L et al. Gadd45a protects against UV irradiation-induced skin tumors, and promotes apoptosis and stress signaling via MAPK and p53. Cancer Res 2002; 62: 7305-7315.

21. Takekawa M, Saito H. A family of stress-inducible GADD45-like proteins mediate activation of the stress-responsive MTK1/MEKK4 MAPKKK. Cell 1998; 95: 521-530.

22. Ito K, Hirao A, Arai F, Takubo K, Matsuoka S, Miyamoto K et al. Reactive oxygen species act through p38 MAPK to limit the lifespan of hematopoietic stem cells. Nat Med 2006; 12: 446-451.

23. Takekawa M, Adachi M, Nakahata A, Nakayama I, Itoh F, Tsukuda $\mathrm{H}$ et al. p53-inducible wip1 phosphatase mediates a negative feedback regulation of p38 MAPK-p53 signaling in response to UV radiation. EMBO J 2000; 19: 6517-6526.

24. Matsuoka S, Huang M, Elledge SJ. Linkage of ATM to cell cycle regulation by the Chk2 protein kinase. Science 1998; 282: 1893-1897.

25. Takai H, Naka K, Okada Y, Watanabe M, Harada N, Saito S et al. Chk2-deficient mice exhibit radioresistance and defective p53-mediated transcription. EMBO J 2002; 21: 5195-5205.

26. Sansom OJ, Reed KR, Hayes AJ, Ireland H, Brinkmann H, Newton IP et al. Loss of Apc in vivo immediately perturbs Wnt signaling, differentiation, and migration. Genes Dev2004; 18: $1385-1390$.

27. Bartkova J, Horejsi Z, Koed K, Kramer A, Tort F, Zieger K et al. DNA damage response as a candidate anti-cancer barrier in early human tumorigenesis. Nature $2005 ; 434: 864-870$.

28. Efeyan A, Serrano M. p53: guardian of the genome and policeman of the oncogenes. Cell Cycle 2007; 6: 1006-1010.

29. Tront JS, Hoffman B, Liebermann DA. Gadd45a suppresses Ras-driven mammary tumorigenesis by activation of c-Jun NH2-terminal kinase and p38 stress signaling resulting in apoptosis and senescence. Cancer Res 2006; 66: 8448-8454.

30. Schramek D, Kotsinas A, Meixner A, Wada T, Elling U, Pospisilik JA et al. The stress kinase MKK7 couples oncogenic stress to p53 stability and tumor suppression. Nat Genet 2011; 43: 212-219.

31. Bartek J, Bartkova J, Lukas J. DNA damage signalling guards against activated oncogenes and tumour progression. Oncogene 2007; 26: 7773-7779.

32. Bowen TJ, Yakushiji H, Montagna C, Jain S, Ried T, Wynshaw-Boris A. Atm heterozygosity cooperates with loss of Brca1 to increase the severity of mammary gland cancer and reduce ductal branching. Cancer Res 2005; 65: 8736-8746.

33. Kinzler KW, Vogelstein B. Lessons from hereditary colorectal cancer. Cell 1996; 87: $159-170$.

34. Mendrysa SM, O'Leary KA, McElwee MK, Michalowski J, Eisenman RN, Powell DA et al. Tumor suppression and normal aging in mice with constitutively high p53 activity. Genes Dev 2006; 20: 16-21.

35. Tront JS, Huang Y, Fornace AJ Jr., Hoffman B, Liebermann DA. Gadd45a functions as a promoter or suppressor of breast cancer dependent on the oncogenic stress. Cancer Res 2010; 70: 9671-9681.

36. Nateri AS, Spencer-Dene B, Behrens A. Interaction of phosphorylated c-Jun with TCF4 regulates intestinal cancer development. Nature 2005; 437: 281-285.

37. Sarbassov DD, Ali SM, Sengupta S, Sheen JH, Hsu PP, Bagley AF et al. Prolonged rapamycin treatment inhibits mTORC2 assembly and Akt/PKB. Mol Cell 2006; 22: 159-168.

38. Yang L, Dan HC, Sun M, Liu Q, Sun XM, Feldman Rl et al. Akt/protein kinase B signaling inhibitor-2, a selective small molecule inhibitor of Akt signaling with antitumor activity in cancer cells overexpressing Akt. Cancer Res 2004; 64: 4394-4399.

39. Nutley BP, Smith NF, Hayes A, Kelland LR, Brunton L, Golding BT et al. Preclinical pharmacokinetics and metabolism of a novel prototype DNA-PK inhibitor NU7026. Br J Cancer 2005; 93: 1011-1018. 